\title{
NEGATIVE IMPACTS OF THE PROTAGONIST'S MARITAL INFIDELITY IN S. J. WATSON'S NOVEL BEFORE I GO TO SLEEP
}

\author{
Sofia Idham Nasution, Zulfan Sahri \\ Faculty of Literature, Universitas Islam Sumatera Utara, \\ Medan, Indonesia \\ e-mail: sofiaidhamn@gmail.com
}

Received: 2020-11-17

Accepted: 2020-11-23

\begin{abstract}
This study is conducted to analyze the context of marital infidelity from novel Before I Go to Sleep and find out its negative impacts among married couple. The negative impacts which are being analyzed in this study are divorce, illness, loneliness, and emotional trauma. This study uses descriptive qualitative method because the process of the result and discussion are accomplished descriptively. The descriptive qualitative method is applied to explain the negative impacts of marital infidelity from the quotations in the novel. The result of this study is to find the implementation of marital infidelity that is still common among married couple; moreover, the implementation only brings a negative impact to one or both parties. The married couple needs to communicate continually to uncover any problem that appears as the time is passing by in order to avoid specifically divorce, loneliness, and emotional trauma.
\end{abstract}

Keywords: divorce, emotional trauma, illness, loneliness, marital infidelity, negative impacts.

\section{Introduction}

The twists and turn of life are always experienced by every human being. The journey of the life is never flat. Sometimes, there are happiness and disaster in human life. The happiness and disaster that happen to each human can improve human life itself or even better, namely improving the quality of their life. In life, human would require a struggle to get their success on their own. Struggle from disaster will create happiness of their life.

Before I Go to Sleep is the first novel by S. J. Watson published in Spring 2011. It became both a Sunday Times and New York Times best-seller and has been translated into over 40 languages, and has become a best-seller in France, Canada, Bulgaria and the Netherlands. It reached number 7 on the US bestseller list, the highest position for a debut novel by a British author since J. K. Rowling. The New York Times described the author as an "out-of-nowhere literary sensation." He wrote the novel between shifts whilst working as a National Health Service (NHS) audiologist (https;//en.m.wikipedia.org).

Before I Go to Sleep is the debut novel of English writer S.J. Watson. In this novel, Christine Lucas wakes every morning thinking she is a carefree, twenty-something woman with a bright future ahead of her. In reality, Christine is a forty-seven year old 
woman who suffers a terrible attack eighteen years before that has left her unable to retain memories. However, with the help of a doctor who specializes in memory disorders, Christine begins to keep a journal that helps her piece together her past and how she ends up as she has. Before I Go to Sleep is a thriller that will leave readers guessing until the final sentence.

Christine Lucas is a forty-seven year old woman who suffered a terrible assault that leaves her with brain damage. Over eighteen years, Christine has been unable to retain new memories. At first, Christine's memory would last only seconds, but over the years, she has recovered enough to retain memories for a full day with the memories disappearing with deep sleep overnight. At the beginning of the novel, Christine wakes up and sees strange man sleeping next to her. She always thinks she is still twenty like a young woman who has had a one night stand with someone's husband. However, Christine learns that this man is her husband.

In this study, the writer analyzes the infidelity experienced by Christine in Novel Before I Go To Sleep. The reason the writer chooses infidelity in this study because the impacts of infidelityresulted in many conflicts experienced by Christine. In this respect, it is logical to take into account the impacts of infidelity as the focus on this study due to the fact that it becomes the essence of the novel. Furthermore, the impacts which are made as the main factors are defined so far to cope with the analysis. Negative impacts are divorce, illness, loneliness, and emotional trauma. Respective data and theories are of high needs to support the whole study and presented in the literature review of this study.

\section{Literature Review}

\subsection{Marital Infidelity}

Infidelity, both extramarital and extradyadic, is a significant problem that seriously affects many relationships. Although the seriousness of affairs is widely recognized, there is no universal definition of infidelity. Fife, et.al (2008: 316) proposed "most committed relationships are characterized by an explicit or implicit commitment regarding intimacy, including both sexual and emotional fidelity to one's partner". They define infidelity as "a betrayal of this implied or stated commitment regarding intimate exclusivity. With infidelity, emotional and/or sexual intimacy is shared with someone outside of the primary relationship without the consent of the other partner". Nevertheless, both scholars and members of the general public have widely divergent perceptions and definitions of infidelity. Blow \& Hartnett (2005: 186) state "infidelity is defined in a myriad of ways and can comprise a number of activities including: 'having an affair,' 'extramarital relationship,' 'cheating,' 'sexual intercourse,' 'oral sex,' 'kissing,' 'fondling,' 'emotional connections that are beyond friendships,' 'friendships,' 'Internet relationships,' 'pornography use,' and others". For the purpose of the current study, marital infidelity will be defined as a secret sexual,romantic, or emotional involvement that violates the commitment to the marital relationship. The reason I choose this definition was because I think there has been a shift in the idea of marital infidelity as just a sexual relationship outside of the marriage to also involving an emotional component.

The other experts define marital infidelity as an act that is felt and experienced as a painful betrayal of a belief and threat in a relationship; this action damages the bound of love and love for a partner (Johnson, 2005) in Chaplin.Asya in Chaplin (2005) says that infidelity as an act of husband (wife) in the form of relationship with someone outside the marital bond that if known to be a legimate partner will be declared an act of harm betraying, violating an agreement, outside commitment. In other words, cheating 
containes. It means dishonesty, distrust, mutual respect with the intention of enjoying relationships with other people so that needs of sexuality are fulfilled (even though it doesn't have to be an equal relationship).

Regardless of the lens utilized to describe infidelity, clinicians and researchers would agree that it is a severe problem with significant consequences for couples (Atkins, et.al.2001; Blow \& Hartnett, 2005; Fife et.al.2012). If infidelity is not problematic for relationships, it would not be responsible for numerous divorces and separations (Abraham,et.al.2001). Typically, people in committed relationships expect emotional and sexual exclusivity of one another (Treas \& Giesen, 2004), yet infidelity continues to be a relatively common problem among couples. According to Hertlein et.al. (2005) fifteen to seventy percent of the married population and thirty percent of dating couples engage in infidelity of some kind. Hansen (1987) concludes that over seventy percent of men and over fifty-seven percent of women have participated in an extradyadic relationship of some kind. Certain variables such as gender have been explored when attempting to understand infidelity; however, perceptions of infidelity might also be influenced by age, sexual orientation, religiosity and previous experience with infidelity, whether committed by oneself, one's partner, or one's parents.

It is clear that marital infidelity is occurring in our society, although to what extent maybe debatable. The large difference in the research percentages may be due to sampling issues, different research designs, or the researchers' different definitions of marital infidelity. Although some discrepancies in the numbers do exist, this does not undermine the importance of continued research in this area because it is obvious, no matter what the statistics, that marital infidelity is occurring within our society. Some individuals are making the decision to have a marital affair. The writer tend to believe that the studies that report a higher incidence of infidelity provide a more accurate picture of extramarital relationships than those that report lower incidents rates.

\subsection{Types of Marital Infidelity}

There have been several types of infidelity cited throughout the literature, although many have not been empirically tested. Most are based on clinicians' experiences of working with clients who have experienced marital infidelity. According to Pittman (1989) in Pour et.al types of marital infidelity are accidental infidelity, romantic infidelity, and marital arrangements as described in the following sections.

\subsubsection{Accidental Infidelity}

Pittman (1989) identified three main types of affairs in his book Private Lies. The first type discussed is called accidental infidelity and is defined as "incidents that were outside the usual patterns of behaviour, happening in extraordinary situations, or offhandedly and without consideration of the consequences". An example of accidental infidelity could be when male and female friends or co-workers find themselves in a life crisis, talking more intimately than normal and becoming closer with each other because of the talk of this crisis. They begin to share thoughts and feelings with each other that they do not share with their respective spouses. This draws them toward each other and away from their spouses. As things progress one person looks to the other for support and, before they realize it a kiss starts things off, leading the two friends to an extramarital relationship. These types of occurrences are more likely to occur when one or both friends are having marital or relationship problems and their friendship boundaries become blurred because of the unexpected intimacy they are sharing with one another. 


\subsubsection{Romantic Infidelity}

The second type of infidelity is called romantic infidelity. According to Pittman (1989), this type is the most dangerous and destructive to the marital relationship because the betraying spouse actually falls in love with the affair partner. When affairs begin, neither partner typically plans on falling in love. Romantic infidelity usually follows one of two patterns. In the first pattern, the intimacy, at first only physical and subsequently psychosocial, begins to increase the attractiveness of the affair partner and decrease the attractiveness of the spouse. In the second pattern, the spouse who has the affair is infatuated with the romantic excitement of being in love. As Pittman (1989) states, the spouse having the affair falls in love with love. This type of affair involves an emotional connection to the affair partner, which pulls him or her further away from his or her spouse.

\subsubsection{Marital Arrangements}

The third type of affair is called marital arrangements, which most people refer to as, swingers. The marital arrangement allows for each spouse to obtain sexual gratification outside of their marriage. Different arrangements have different rules for engaging in the sexual behaviour outside the marriage. Some spouses agree to not ask about their outside behaviour, whereas others must partake in the sexual activity with their spouse and the other person together. Usually, these types of arrangements have been discoverof emotional involvement but not involving sexual intercourse. In the second, sexual involvement consists of sexual intercourse but no emotional involvement.

The third and final type is a combination of the previous two types consisting of both a strong sexual and emotional relationship. The later has been found to be significantly more damaging to the marriage than the other two types alone. It is much more difficult to repair the marital relationship when the spouse having the affair is both emotionally and sexually connected to the affair partner. Many times this experience and the feelings he or she is having resemble the time he or she fell in love with his or her spouse, which gives the illusion of a happier life with the affair partner. It is also damaging to the marital relationship because the spouse, who is having the affair, is giving the affair partner the majorityof the time, energy, if not all,emotional connectedness, talking, and sexual pleasure, rather than sharing this with his or her spouse. This creates a large gap in the marital relationship.

\subsection{Impact of Marital Infidelity}

Marital infidelity has serious negative consequences for couples and their children. Marital infidelity, regardless of the type, results in major conflicts in spouses' relationships. For social, cultural and psychological reasons, extramarital affairs may have different impacts on marital satisfaction and mental wellbeing for different couples. Parental infidelity produces anxiety, confusion and distress among children. It also increases the likelihood of adult children involving in marital betrayal themselves. Marital infidelity has been associated with kinds of emotional responses and behaviors such as increased anxiety and depression, suicidal ideation, along threats of divorces and physical aggression. Ben-Ami \& Baker (2012) show that marital Infidelity lead family conflict and distress. It may cause divorce, separation, and other family changes that its consequences are mental distress like anxiety in children. According to Mao and Raguram (2009) in Jeanfreau, infidelity is highly undesirable in the marriage institution, and can negatively impact the level of trust between spouses. Marital infidelity is usually conducted in 
silence and therefore causes one partner to feel not only hurt, but also betrayed by the other. Marital infidelity happens in different social groups.

A study showed when military couples are separated for long times, and have contact to the internet, it may not be odd for them to become emotionally engaged with cyber partners. Marital infidelity makes distress in partner intimacy and reduces relationship satisfaction in both spouses. Further, the victims and doers of marital infidelity also frequently experience negative outcomes, for example decreased selfesteem, increased risk of mental health issues, shame and guilt feelings, and depression. Identifying psychological characteristics that may be associated with a risk of perpetrating infidelity may help interventions to better target at risk partners. Studies have shown that infidelity can have negative effects on the relationship, and may be the most fear and devastating experience threatening a marriage, which may lead to divorce. Therefore, marital infidelity can display as a strong predictor of divorce. The impact of parental infidelity on children can vary based on the child's gender, age, and even culture. Children's' state of cognitive and emotional development during this sensitive period may inhibit or perpetuate the exercise of unilateral loyalty to a parent.

\subsection{Negative Impacts of Marital Infidelity}

The fatal blow to any marriage is an adulterous affair where one or both spouses think they finally found his or her soul mate. Adultery is a sexual relationship in which a man or women has with another partner rather than his/her own spouse. Adultery is seen as a great $\sin$ in the society. Adultery maliciously interferes with marriage relations, and sometimes opens the door to divorce. Committing adultery is not uncommon to say the least. Adultery seems more rampant than ever these days. Society has come up with phrases which excuse or soften the perception of adultery such as: fooling around, sleeping around, having a fling or an affair. These phrases try to justify adultery as being guilt-free and as if it hurts no one when in actuality it hurts all involved. Adultery shatters trust, intimacy, self-esteem; it breaks up families, ruins careers and leaves a trail of pain and destruction in its path(Updike, 2011: 87).

Adultery will only bring pain to the relationship already established, though the persons involved have got some certain paradigm of freedom. Adultery will affect not only the physical but also the spiritual relationship of the couple. For men and women there are many reasons they have committed or are committing adultery. For the most part many who have affairs have a good sex life but come from marriages with little or no intimacy. When a spouses needs are not met many marriages tend to become more vulnerable to an extramarital affair. Often the failure of men and women to meet each other"s needs is due to the lack of knowledge rather than a selfish unwillingness to be considerate. The negative impacts of infidelity are explicated in the following section:

\subsubsection{Divorce}

While cheating does not always end in divorce, it can have a devastating impact. It is probably the most damaging thing that can happen to a marriage. Bell (1979) state the divorce is a break up of legal ties that unite married couples in one household, socially divorce builds awareness on each individual that their marriage has ended. Bell added that divorce must be distinguished from a case where one partner leaves his family for a long time (desertion).

Hurlock (1994), states that divorce is a calmination of the settlement of a bad marriage, and what happens if between husband and wife are no longer able to find ways 
to solve problems that can satisfy both parties, it should be realized that many marriages do not produce happiness but end divorce. This is because the marriage is based on religious, moral, economic conditions, and other reasons. Separation or cancellation of marriage can be done legally or secretly and sometimes there are also cases where one partner (wife / husband) leaves the family (away).

So, divorce is the abolition of marriage with the decision of the top judge the demands of one of the parties to the marriage. The point is that the law does not allow divorce with agreement only between husband and wife.

\subsubsection{Illness}

On top of the dangers of being exposed to different sexually transmitted diseases when a partner cheats, illness can occur. Most people would agree that being cheated on is a miserable experience. It not only has the power to make you feel awful, but also ill. Research over the past few decades provides evidence that suggests infidelity can, in fact, lead to illness. This research suggests that infidelity can be a factor in the development of mental illness and can also have consequences for a person's physical health. There is a growing school of thought that the discovery of a partner's infidelity can be a psychologically traumatic event significant enough to trigger post-traumatic stress disorder (PTSD). In the novel Before I Go To Sleep Christine as the protagonist got amnesiac short term beacuse of infidelity. Memories that are of short to medium-lived persistence are defined as short term, whereas working memory have a time-lapse of seconds to minutes and long-term memory which have a memory persistence of decades (Gazzaniga.et.al 2013). In sensory memory, memory lasts (at most) for a couple of seconds. For hearing, sensory memory is called echoic memory and as for vision, it is called iconic memory. In principle, these form of memories can retain eextensive informetion, however only for a very short time. In addition, short-term memory, the course of time last from seconds to minutes compared to sensory memory. The capacity of short-term memory is limited (Gazzaniga.et.al 2013).Cheating is one of the easiest ways to damage a relationship. The reason infidelity is the closest thing to impossible to resolve and work through is because it completely shatters the most basic foundation of a relationship: trust. Cheating can collapse even the strongest bonds and is especially dangerous because it has the power to implode your relationship (https://www.Beliefnet. Com/love-family/relationships/6-fatal-consequences-of-adultery).

\subsubsection{Loneliness}

Infidelity is lonely and isolating. Loneliness is a universal human emotion that is both complex and unique to each individual. Because it has no single common cause, the prevention and treatment of this potentially damaging state of mind can vary dramatically. While common definitions of loneliness describe it as a state of solitude or being alone, loneliness is actually a state of mind. Loneliness causes people to feel empty, alone, and unwanted. Loneliness is linked to an increased risk of heart disease, viral infections, cancer and Changes in the immune system. They assure that a person's social environment can affect their health, with those who are socially isolated are exposing to a high risk of mortality than people who are not. This shows that social relationship is important without which no one could survive in life (Psaltis: 2015). 


\subsubsection{Loss of Trust and Intimacy}

A fatal consequence of adultery is broken trust and loss of intimacy. An entangled affair is always the result of an intimacy deficit in the marital relationship. Part of the lure of the affair for an unfaithful spouse is the opportunity to be himself or herself in his or her own little private world they construct with another person. They desperately needed that freedom to be themselves, to be accepted and appreciated. They did not want to pretend or stay within a certain mold, since it is a brand new world with no rules expect those they chose to create with a new partner. It is important to identify what is missing in the marital relationship and repair that loss(https://www.Beliefnet. Com/lovefamily/relationships/6-fatal-consequences-of-adultery).

\subsubsection{Guilt and Shame}

Guilt and shame are big components of adultery - both for those who cheat and for the wounded spouse. When infidelity is discovered in a marriage, and brought out in the open by the couple, usually there is an overt or covert agreement not to tell or hide the fact from others, except perhaps for a close family member or friend. And, they are told not to tell. It is as if infidelity is a black mark. It's embarrassing. One would think this is true for the cheating spouse, which it is most of the time. But even in more situations it is the wounded spouse who feels the embarrassment and shame. The wounded spouse wants to shrink, wants to hide and indeed feels as if he or she is tainted. The persistent thoughts can be "there must be something wrong with me," "something was wrong with the marriage," or "I failed." Life becomes constricted (https://www.beliefnet.com/love-family/relationships/6-fatal-cons

Equences-of-adultery).

\subsubsection{Emotional Trauma}

Emotional breakdown is bound to happen when your spouse breaches the trust. You may fall into a traumatized state. As a victim, you will be trying to discover the reasons and causes of cheating or will begin the self-blame-game. Infidelity in a relationship will take you through a roller coaster of emotions with you feeling surrounded by negativity. Trauma is described by Creamer as a personal experience that confronted someonewhich is threatened death or serious injury that involves a family member or other close associate. The person's response to the event must involve intense fear and helplessness Trauma can affect the whole person, including changes in body, mind, emotions, and behavior. But each person's specific reactions depend on the particulars of the event and the person's unique self and history.

The are severals reactions refers to the body to react. Physical reaction is when thesufferer may have a rapid heartbeat, muscle tension, nervousness, and sleep difficulties. Then, Mental reaction is impact thatcan disrupt thoughts, it may pop into mind unannounced and unwanted or not. This can include a sense of being unable to protect yourself and feelingunprotected or threatened by others. Emotional reaction refers to feeling of fear, inability to feel safe, frequently or severely threatened continue to feel unsafe, unprotected or threatened by others even when circumstances no longer feeling helpless. Being a victim of a natural disaster, crime, accident, orrepeated abuse can make us realize how helpless we can be. Last is behavioral reactions, isolated from others, it mayfeel safersufferer or more comfortable to be alone and avoiding places or situations, reminders of the trauma may bring back painfuland unpleasant memories, may find 
Negative Impacts of The Protagonist's Marital Infidelity in S. J. Watson's Novel Before I Go To Sleep, Sofia Idham Nasution, Zulfan Sahri

sufferer self avoiding them even if it meansdisruptions on day to day life (Rosendbloom and Williams, 1999).

\section{Research Method}

In exploring this research the writer uses descriptive method. Descriptive research is unique in the number of variabels employed. Like other types of researh, descriptive research can include multiple variables for analysis, yet unlike other methods, it requires only one variable (Borg \& Gall. 1989). Therefore, the research design adopted in this study is descriptive qualitative because the process of the analysis and the findingsare accomplished descriptively.

\section{Discussion}

The analysis focuses on the negative impacts of marital infidelity. They are divorce, loneliness, emotional trauma, and illness. All of these become the presented points of analysis which are primarily based on S.J Watson's Before I Go to Sleep.

\subsection{Divorce}

Divorce is the most deplorable situation after marriage life while infidelity does not always end in divorce; it can have devastating impact. The divorceis a break up of legal ties that unite married couples in one household, socially divorce builds awareness on each individual that their marriage has ended. As described in chapter II in 2.6.1.1, divorce is a culmination of the settlement of a bad marriage. People should realize that many marriages do not produces happiness will end up divorce. In the novel Before I Go to Sleep, Ben divorces Christine after she commits infidelity. Their divorce is seen in the following:

"When I found out that bastard had left you, I couldn't just leave you in that place. I knew you'd want to be with me. I knew it was the best thing for you. I had wait for a while, wait until I knew there was no one still there to try and stop me, but who else would have looked after you?"(Watson, 2011: 342)

The quotation describes that Ben leaves Christine since a very long time. He leaves Christine in the hospital after divorce, and never comes back. The reason Ben leaves because he cannot stand looking at Christine with her illness so that she cannot remember him and their son. Therefore, Mike who always looks after her comes and takes her with him. Mike pretends that he is Christine's husband, so that the hospital allows him to take Christine. Christine who has amnesia and cannot remember anything in her life follows Mike assumes that Mike is her husband. It is also seen that Mike lives with Christine after she gets divorced with Ben.

\subsection{Loneliness}

Loneliness is a universal human emotion which brings about complexity and uniqueness to each individual. Because it has no single common cause, the prevention and treatment of this potentially damaging state of mind dramatically. As explained in chapter II in 2.6.1.3, it causes people to feel empty, alone, and unwanted. Infidelity is lonely and isolating. In the novel Before I Go to Sleep, lonelinessoccurs when Christine lives alone in her housewhile Mike goes to work and also when she is in the hospital before Mike takes her with him. However, she feels more lonely when she knows that she 
could not meet her son anymore. The following quotation proves loneliness that happensto her:

"I feel like a child kept out of school, left alone at home while her parents go to work. Don't touch anything, I imagine him saying. Don't forget to take your medicine."(Watson, 2011: 13)

The quotation above points out that Christine feels so lonely when Mike leaves her to work. She feels isolated at home because she cannot do anything without Mike. Even, she cannot remember a place of things that she looks for. Christine feels like a child who cannot do anything without their parents. She is so confused about what exactly happens to her. She is wondering whether she keeps doing nothing all day without Mike. Moreover, she has to leave out of her work because she cannot remember a thing when she wakes up for tomorrow. Therefore, she has to stay at home everyday.Other evidence which shows us the loneliness is when the time comes for Christine to realize that she has a baby but cannot remember him.

\subsection{Emotional Trauma}

Emotional trauma is bound to happen when your spouse breaches the trust. You may fall into a traumatized state. Emotional reaction refers to feeling of fear, inability to feel safe,frequently or severely threatened continue to feel unsafe, unprotected or threatened by others even when circumstances no longer feeling helpless.

As verified in Chapter II in 2.6.1.6, being a victim of a natural disaster, crime, accident, orrepeated abuse can make us realize how helpless we can be. Last is behavioral reactions, isolated from others. Avoiding places or situations, reminders of the trauma may bring back painfuland unpleasant memories and may find sufferer self avoiding them even if it meansdisruptions on day to day life.In the novel Before I Go to Sleep, emotional trauma occurs after Christine gets amnesia. The condition of such an emotional trauma is depicted as follows:

"I woke for real, then, with another, different voice call me. "Chirstine! Chris! Are you okay?" It said, and with relief I realized it was Ben and I had been dreaming. I opened my eyes. I was lying in a bath, My clothes folded on a chair beside me, pictures of my life taped to the pale blue tiles above the sink. "Yes" I said. "I'm fine. I just had a bad dream.”(Watson, 2011: 126)

The quotation above describes that Christine gets an emotional trauma. She often has a bad dream. A bad dream that often happens is her memory about the past, but Christine does not know about it; she just feels like it is a bad dream. She is confused to differentiate whether her dream is an imagination or a dream. She always dreams of the same situation. She was in the bathroom looking for someone's help. She knows that she is in the different bathroom in her dream; it is not in her house. She begins to confuse about the dream that always comes to her like a nightmare.

\subsection{Illness}

Most people would agree that being cheated on is a miserable experience. It has not only the power to make us feel awful, but also ill. As described in chapter II in 2.6.1.2, research over the past few decades provides evidence that suggests that infidelity can, in fact, lead to illness. In the novel Before I Go To Sleep, Christine as the protagonist gets 
amnesiashort term beacuse of infidelity. Memories that are of short to medium-lived persistence are defined as short term, whereas working memory has a time-lapse of seconds to minutes and long-term memory which have a memory persistence of decades.

In sensory memory, memory lasts (at most) for a couple of seconds. For hearing, sensory memory is called echoic memory and as for vision, it is called iconic memory. In principle, these form of memories can retainextensive information, however, only for a very short time. In addition, in a short-term memory, the course of time lasts from seconds to minutes compared to sensory memory. The capacity of short-term memory is limited.In the novel,illness (amnesia) occurs after Christine has an affair with Mike. The following quotation proves illness (amnesia) that happens in the novel:

"You had accident,' he says. 'A bad accident. You suffered head injuries. You have problems remembering things.' 'What things?' I say, meaning, surely not the last twenty-five years? ' What things?'. He steps toward me again, approaching me as if I am a frightened animal. 'Everythings' he says. ' Sometimes starting from your early twenties. Sometimes even earlier than that." (Watson, 2011: 6-7)

In the above-mentioned quotation, it illustrates that Christine gets amnesia after having a bad accident. She does not even know that Mike lies to her about the reason of her illness. Mike says that she sufferes head injuries; every day when Christine wakes up in the morning; he always says the same thing over and over. In fact, the reason of her illness is Mike. Mike hit her so badly on the last time they met in the hotel. When Christine wants to end their affair, Mike is constantly angry with her, and wants to tell Ben about their relationship. Therefore, when Christine wants to stop him, Mike slaps her and they start to fight until Christine is badly injured and Mike leaves her in a parking lot near the airport. Italso shows that Christine only can remember memories from her early twenties and sometimes earlier than that. The following is the proof showing that Christine gets amnesia.

After analyzing the negative impacts of marital infidelity in the novel Before I Go to Sleep, there are some findings which can be presented. The implementation of marital infidelity is still common among married couple. Marital infidelity will only bring a negative impact to one or both parties. Divorce often happens after one's partner committed infidelity. Loneliness and Emotional trauma usually occurs in someone's life who has committed infidelity or both spouses. Marital Infidelity may cause an illness for both of the spouses. Marital infidelity also brings a negative impact for the children.

\section{Conclusion}

Having conducted an analysis on the negative impacts of marital infidelity, there are several points that need to be concluded. It is concluded that there are negative impact of marital infidelity in the novel Before I Go to Sleep. There are four negative impacts that can be found in this novel. The negative impacts of marital infidelity are divorce, loneliness, emotional trauma, and illness. Christine gets divorce from her husband after she commits infidelity. Ben divorces Christine after she gets amnesia and he leaves her in the hospital. Loneliness occurs when Christine lives alone in her house while Ben alias Mike go to work and also when she is in the hospital before Ben takes her with him. However, her loneliness appears when she knows that she could not meet her son anymore. Emotional trauma occurs after Christine got amnesia. The emotional trauma is realized in a bad dream after she gets amnesia, and she cannot differentiate between 
reality and imagination. Illness (amnesia) occurs after Christine commits infidelity with Mike, When Mike hits Christine when she wants to leave him.

\section{References}

Abraham, et.al. (2001). Infidelity, race, and gender: An evolutionary perspective on asymmetries in subjective distress to violations-of-trust. Current Psychology: Developmental, Learning, Personality, Social, 20(4), 337-348.

Atkins, et.al. (2001). Understanding infidelity: correlates in a national random sample. Journal of Family Psychology, 15(4), 735-749. https://www.researchgate.net/publication/325671754_Understanding_infidelity_ Correlates_in_a_national_random_sample

Bell, R. R. (1979). Marriage and Family Interaction. 5th edition. Illinois: The Dorsey Press.

Borg, W.R. dan Gall, M.D. (1989). Educational Research: An Introduction, Fifthy Edition. New York: Longman.

Blow, A.J. \& Hartnett, K. (2005). Infidelity in committed relationships I: A methodological review. Journal of Marital and Family Therapy, 31(2), 183-216. https: // psycnet. apa. Org / doi / 10.1111 / j. 1752-0606.2005.tb01555.x

Buwono Nuri, et.al. (2017). Marital Disharmony in Jackie Collins' Hollywood Wives. Language Literacy,Volume 1 Number 1, Desember 2017, Pages 97 - 118. https:// jurnal.uisu.ac.id / index.php / languageliteracy/article/view/248/242

C.P Chaplin.(2005). Kamus Lengkap Psikologi, Terjemahan Kartini Kartono, Raja Grafindo: Persada, Jakarta.

Fife, et.al. (2008). Treating Infidelity: An Integrative Approach. The family journal: counseling and therapy for couples and families, 16, 316-323. https://pdfs.semanticscholar.org/80bc/84446b60acda6c20b87036b87659e16e982 3.pdf

Gazzaniga, M. S., Ivry, R. B., \& Mangun, G. R. (2013). Cognitive neuroscience: The biology of the mind (4th ed). New York, NY: W.W. Norton \& Company.

Hansen, G.L. (1987). Extradyadic relations during courtship. Journal of Sex Research,23,382-390. https:// www . tand fon line . Com / doi / abs / $10.1080 / 00224498709551376$

Hertlein, et.al. (2005). Infidelity. Journal of Couple \& Relationship Therapy: Innovations in Clinical and Educational Interventions, 4: 2-3, 5-16. https://www.academia.edu/35863661/Journal_of_Couple_and_Relationship_The rapy_Innovations_in_Clinical_and_Educational_Interventions_Polyamory_Expe riences_of_Power_from_Without_from_Within_and_in_Between

Hurlock, E. B. (1994). Psikologi Perkembangan, Suatu Pendekatan Sepanjang Rentang Kehidupan. Jakarta : Erlangga. Bandung: Pustaka Hidayah, 2005

Jeanfreau, Michelle Marchese. (2009). A qualitative study investigating the decision making process of women's participation in martial infidelity. Manhattan,Kansas : Kansas State University.

Lutters, Elizabeth. (2006). Kunci Sukses Menulis Skenario. Jakarta: Grasindo.

Pour, et.al. (2019.)Psychology \& Psychological Research International Journal : Infidelity in Marital Relationship. Faculty of Educational Studies, University Putra Malaysia, Malaysia : Medwin Publisher. https://medwinpublishers.com/PPRIJ/PPRIJ16000200.pdf 
Psaltis, Charis, et.al. (2015). Social Relations in Human and Societal Development.ResearchGate.https://www.researchgate.Net/publication/26715471 8_Social_Relations_in_Human_and_Societal_Development. Retrieved on Monday 14,October 2019.

Rosenbloom, Dena., and Williams, Mary Beth. (1999). A workbookfor healing: Life After Trauma Second Edition. Guildford Publications, Inc.pdf.

Spitzberg, Brian. (2015). Extramarital Affairs. San Diego : San Diego State University. https://www.researchgate.net/publication/313523897.

Updike, John. (2011). The Couples. Belmont: Watdish.

Watson, S.J. (2011). Before I Go To Sleep. HarperCollins Publisher: New York. ,. (2019). Before I Go to Sleep. https;//en.m.wikipedia.org.Retrieved on Friday 26, July. 2019

,. (2019). Six fatal consequences of adultery.https://www.Beliefnet.com/lovefamily/relationships/6-fatal-consequences-of-adultery. Retrieved on Thursday 8, August 2019.

Major

effects

extramarital affairs. https://www.Onlymyhealth.Com/major-effects-extra-marital-affairs1332313120. Retrieved on Thursday 8, August 2019.

(2019). Loneliness causes effects and treatments. https://www.Verywellmind.com/loneliness-causes-effects-and-treatments2795749. Retrieved on Wednesday 11, September 2019. 